\title{
Perceptions of School Bullying, Social Support, and Stress Among Korean Adoptees in U.S. White Families: A Pilot Study
}

\author{
Eun-Jun Bang, Ph. D., MSW (Corresponding author) \\ Professor/ Department of Social Work \\ Northeastern State University \\ 3100 E. New Orleans Street \\ Broken Arrow, Oklahoma, USA
}

Tel: 1-918-449-6864 E-mail: bang@gmail.com

Kathlyn Shahan, Ph. D., MSW

Associate Professor/ Department of Social Work

Northeastern State University

609 N Grand Avenue

Tahlequah, OK 74464, USA

Tel: 1-918-444-3508

E-mail: shahan@nsuok.edu

Aesha John, LMSW, Ph.D.

Associate Professor/ Department of Social Work

Texas Christian University

Department of Social Work

TCU Box 298750

Fort Worth, Texas 76129, USA

Tel: 1-817-257-8005

E-mail: aesha.john@tcu.edu 


\title{
Macrothink

Christopher C. Garland, Ph. D., MSW

Assistant Professor

Department of Social Work

Northeastern State University

609 N Grand Avenue

Tahlequah, OK 74464, USA

Tel: $1-918-444-3507$

E-mail: garlancc@nsuok.edu

Received: Sep. 20, 2019 Accepted: Oct. 30, 2019 Published: Jan. 15, 2020

doi:10.5296/ijssr.v8i1.15485 URL: http://dx.doi.org/10.5296/ijssr.v8i1.15485

\begin{abstract}
Although there are numerous research studies on post adoption services to improve wellbeing of adopted children and their adoptive families, there is scarce research on school adjustment of adopted children. To address this gap, the current study examined the link between experience of school bullying and psychological stress among Korean children adopted into U.S. white families. In addition, it examined the role of social support in moderation the association between the experience of being bullied and stress. One hundred sixty-one were mailed to adoptive families through Dillon International Adoption Agency. Thirty-one children completed and returned the packets. Data analysis utilizing independent t-test and ANOVA indicated that peer intervention and adults or teachers' intervention could be a moderating factor to lower stress levels among Korean adoptees. The paper includes research implications of these findings as well as limitations of the study.
\end{abstract}

Keywords: Korean adoptees in white families, school bullying, bullying prevention, social support, stress 


\section{School Adjustment of Asian Adoptees in the U.S. Families}

According to the U.S. Bureau of Consular Affairs' intercountry adoption reports from the past 10 years, approximately 10,000 children, ages 0-18 year, from various foreign countries are adopted by U.S. based families annually ("Annual Report on Intercountry Adoption", n.d.). Interestingly, a majority of international adoptees come from Asian countries (e.g. China, South Korea). Whereas the process of adoption is a potentially stressful transition for any child (Brodzinsky, Smith \& Brodzinsky, 1998; Nickman et al., 2005; Saiz \& Main, 2004), this stress may be significantly elevated for Asian born children who have to adapt to the sociocultural context of their U.S. adoptive family. Indeed, it is crucial to examine the psychosocial adjustment of Asian born children adopted into U.S. families.

\subsection{Psychosocial Adjustment of Asian Adoptees}

Past research on psychosocial adjustment highlight some of the challenges encountered by Asian adoptees. For example, Mohanty and Newhill (2011) found that when Asian adoptees felt marginalized, they tended to have lower self-esteem, but on the other hand; when adoptive parents supported racial socialization, adoptees felt less isolated, which in turn, raised their levels of self-esteem. Similarly, when adoptees felt at ease with their adopted status, they enjoyed higher levels of wellbeing (Mohanty, 2013). Lee, Lee, Hu, and Kim (2014) found that as compared to the Asian adoptees that were well-integrated into the mainstream culture, adoptees with strong ethnic pride and preference for ethnic language, food, etc. were more likely to demonstrate negative outcomes (e.g. externalizing problems, substance use) when they were subject to discrimination.

Whereas these findings are important in identifying the predictors of adoptees' wellbeing, they focus mostly on internal psychological struggles (e.g. self-esteem, ethnic identity). With few notable exceptions, past studies unfortunately have failed to examine what the Asian born children adopted into U.S. families encounter in their social environment. One exception is Docan-Morgan's (2010) study with Korean adoptees, which sheds light on this important aspect of Asian adoptees' adjustment. The study examined adoptees' retrospective memories of intrusive interactions; intrusive interactions were conceptualized as inappropriate questions and comments from people outside the family (e.g. relatives, neighbors, and strangers) due to the 'visibility' of the adoption. An example of intrusive interaction is an outsider asking the adoptive family how much money they spent on the adoption, in the children's presence. All of the participants of Docan-Morgan's (2010) study reported that they had encountered such interactions several times in their life; whereas some comments were innocuous, others were more malicious. All such encounters evoked negative emotions ranging from embarrassment to anger among the participants. The above findings not only bring to light the hostility that adoptees encounter in their social environment, but also underscore the need to further examine potential for hostility and aggression in various social settings that are salient in children's lives. Since school is a setting in which most children spend a significant portion of their day, it is important to investigate whether Asian adoptees encounter any aggression in the school setting. 


\subsection{School Bullying}

Although we could not find any bullying studies with international adoptees in the U.S., in a study carried out in Finland with international adoptees, $20 \%$ of the children reported being victimized. Interestingly, children with an attachment disorder, academic difficulties, and poor social skills were more likely to be bullied compared to children without such challenges (Raaska et al., 2012). It is possible that the difference in appearance between Asian born adoptees and their adoptive families, or visible adoption, may make it challenging for school-age Korean adoptees to fit in with their peer group. Indeed, past research on bullying and micro-aggression indicates that children perceived as different from the norm are at greater risk for being bullied by their peers (Son, Parish, \& Peterson, 2012). Considering the well-documented effects of bullying on mental and physical health (Denny, Clark, Fleming, \& Wall, 2007; Kaltiala-Heino, Rimpelä, Rantanen, \& Rimpelä, 2000), our study sought to examine whether Korean adoptees in the United States experience school bullying.

\subsection{Stress and Social Support}

A number of studies on bullying demonstrate clear and conclusive evidence regarding negative psychological outcomes among bully victims. For example, in one study with 11-16-year-old adolescents, the participants that identified as victims reported a higher level of loneliness as compared the other participants (Estevez, Murgui, \& Musitu, 2009). Carney, Hazler, Oh, Hibel, and Granger's (2010) study with sixth graders produced consistent findings on victimization and anxiety; the participants that reported greater exposure to bullying had higher levels of anxiety. Similarly, Hawker and Boulton's (2000) extensive meta-analysis of studies conducted between 1978 and 1997 on psychological maladjustment among bully victims, showed significant effect sizes of peer victimization on various psychological adjustment indicators such as anxiety, depression, and self-esteem. Given this strong evidence linking bullying with negative psychological outcomes, we assessed whether Asian adoptees that reported being victims of bullying reported higher levels of perceived stress as compared to children that reported not being bully victims.

In addition to perceived psychological stress, a few recent studies have attempted to identify factors that potentially play a protective role in shielding victims from negative effects of bullying. As such, this line of research is consistent with the stress and resilience framework, which proposes that individuals can successfully overcome negative life events and experiences when they are equipped with certain coping resources (Kaplan, Turner, Norman, \& Stillson, 1996). According to Polk (1997) an important coping resource could be in the form of social relationships or the presence of supportive persons in one's environment. This notion has been tested and verified in various fields of research.

In the context of school bullying research, this theory would imply that social support from peers and teachers perhaps buffer bully victims from negative psychological effects, such as stress. A few studies have examined this proposition and yielded interesting findings. In Davidson and Demaray's (2007) study with middle school students, adult support moderated the association between bullying and internalized distress such as sadness and anxiety. 
Similarly, Holt and Espelage (2007) assessed stress and depression among adolescents as well as adolescents' use of peer and parental network. In their participants, who identified as victims, higher perceived social support exacerbated the effects of bullying on stress. But at the same time, children that identified as non-victims reported higher levels of support as compared to victims. Given these promising findings, we assessed the role of teacher and peer support in moderating the link between bullying and stress among Korean adoptees. In other words, we assessed whether bullying victims that reported positive teacher and peer support encountered lower levels of stress as compared to victims that did not have a similar social support.

In summary, the present research sought to answer the following questions: (a) Is there any relationship between school bullying and stress levels among Korean adoptees in US based white families? (b) and How do different types of social supports moderate stress caused by school bullying among Korean adoptees in white families? Based on past research we expected to find a positive association between bullying and stress. However, we hypothesized the link between bullying and stress to be moderated by the presence of positive support from peers and teachers.

\section{Method}

\subsection{Participants}

In accordance with the procedure approved by the university Institutional Review Board, participants were recruited across the United States through Dillon International, an adoption agency based in Tulsa, Oklahoma. The target population of this study was middle school and high school aged Korean adoptees who were adopted in the United States White families.

The agency mailed out 161 packets to families that had previously used their services. Thirty-one participants (19\%) completed and returned the packets; ten (32\%) participants were male and the remaining were female $(n=21,68 \%)$. They ranged in age from 9-16 years $(M=13, S D=1.61)$. Eighteen participants $(84 \%)$ reported that they have one or more siblings. In terms of bullying experience, 14 participants (45\%) reported that they had experienced racial bullying, and eight participants (26\%) stated they had been bullied with mean names or comments about their race and color. Also, three participants (10\%) reported that they had been bullied because their ethnicity was different from that of their adoptive family members. Nineteen participants (61\%) reported that they have seen often and almost always their teachers or other adults at school try to put a stop to a student being bullied at school, and eight participants (26\%) reported that they have seen often and almost always other students try to put a stop to a student being bullied at school.

\subsection{Procedure}

A quantitative research design was used for the study. As previously mentioned, the data were collected in collaboration with the Dillon International Adoption agency. The agency sent out a packet to potential participants; each packet included study information, a consent form, questionnaires, and a postage paid, self-addressed envelope. The questionnaires in the packet were a demographic questionnaire, Olweus Bullying Questionnaire (Olweus, 2007) to 


\section{Macrothink}

investigate types and causes of school bullying, Perceived Stress Scale (PSS; Cohen, Kamarck, \& Mermelstein, 1983) to measure stress level, and social provision scale (Cutrona, Russll, and Rose, 1984). The participants were requested to return completed surveys in a sealed envelope to the first author for data analyses. The survey data were analyzed to examine the effects of bullying, stress level and moderating role of social support.

Table 1. Demographic information for participant $(N=31)$

\begin{tabular}{|c|c|c|}
\hline Characte & stics & Number $(\%)$ \\
\hline \multicolumn{3}{|l|}{ Gender } \\
\hline & Male & $10(32 \%)$ \\
\hline & Female & $21(68 \%)$ \\
\hline \multicolumn{3}{|c|}{ I have experienced racial bullying } \\
\hline & Yes & $14(45 \%)$ \\
\hline & No & $17(55 \%)$ \\
\hline \multicolumn{3}{|c|}{ I have been bullied with mean names of comments of my race and color } \\
\hline & Yes & $8(26 \%)$ \\
\hline & No & $23(74 \%)$ \\
\hline \multicolumn{3}{|c|}{$\begin{array}{l}\text { How often do the teachers or other adults at school try to put a stop it when a student is being } \\
\text { bullied at school }\end{array}$} \\
\hline & Almost Never & $5(16 \%)$ \\
\hline & Once in a while or sometimes & $7(23 \%)$ \\
\hline & Often or almost always & $19(61 \%)$ \\
\hline \multicolumn{3}{|c|}{$\begin{array}{l}\text { How often do other students at school try to put a stop to it when a student is being bullied at } \\
\text { school }\end{array}$} \\
\hline & Almost Never & $4(47.8 \%)$ \\
\hline & Once in a while or sometimes & $47(52.2 \%)$ \\
\hline & Often or almost always & \\
\hline
\end{tabular}

\subsection{Measures}

\subsubsection{Demographic Questionnaire.}

The demographic questionnaire sought information on participants' age, gender, the size of their adoptive family, and their attendance at Heritage Camps for adoptive families in the past. Questions about participants' experience with bullying such as "Did you ever experience racial or other types of bullying because of your ethnicity?" and "Have you been bullied because of your different ethnicity from your family members?" were asked as well. 


\subsubsection{Olweus Bullying Questionnaire.}

A revised version of the Olweus Bullying Questionnaire was used for this study. The Olweus Bullying Questionnaire is a standardized, validated multiple choice-style questionnaire that seeks information on various aspects of bullying problems such as the exposure to different types of physical, verbal, and racial bullying as well as any other concerns related to bullying in school (Olweus, 2007). The questionnaire includes a total of 40 self-report items that ask whether or not the student had been bullied or had bullied other students, and assesses frequency of bullying, how often children report bullying to teachers or authority figures, and also whether or not teachers and other students intervened to stop the bullying.

\subsubsection{Perceived Stress Scale.}

The Perceived Stress Scale (PSS; Cohen, Kamarck, \& Mermelstein, 1983) was used in this study to measure participants' stress level. The PSS is a widely used 10-item Likert type scale ranging from never to very often; it measures an individual's life stress apart from any specific life event that might cause stress. Participants are asked how often they felt a certain way such as "In last month, how often have you felt confident about your ability to handle your personal problems?" The PSS has been tested for internal consistency and found to be sufficient with Cronbach's alpha ranges from 0.84 to 0.86 (Cohen et al., 1983). For this study, the PSS was found to be reliable at 0.91 .

\subsubsection{Social Provision Scale.}

The Social Provision Scale is a 24-item Likert scale that measures the provisions of social relationships (Cutrona, Russll, \& Rose, 1984). This scale predicts an individual's relationships with other people as sources of stress or lack of stress by asking questions on participants' perceptions of their social support network. For each question, participants report how strongly they agree to disagree with a given statement. Statements include: "I have a relationship where my competence and skills are recognized." This scale has been tested for test-retest reliability and found to be sufficient with coefficients range from .37 to .66 (Cutrona, Russll, \& Rose, 1984).

\subsection{Data Analysis}

All the analyses in this study were conducted using SPSS 21. Descriptive statistics were generated for the demographic information of study participants. An independent $t$-test was conducted to compare the difference in stress level between Korean adoptees who experienced school bullying and Korean adoptees who did not experience school bullying. Another independent $t$-test was used to compare the difference in stress among Korean adoptees who witnessed other students put a stop to bullying and those who did not witness other students intervene. Finally, a one-way ANOVA was used to examine whether the frequency of teachers' intervention could be a moderating factor to reduce bullied adoptees' stress level. 


\section{Results}

This study found that there is a significant relationship between school bullying and stress levels among Korean adoptees in trans-racial families. The study showed that Korean adoptees who experienced school bullying had a higher level of stress than Korean adoptees who did not experience school bullying $[t(30)=-2.1, p<.045]$. Also, an independent t-test found that Korean adoptees who witnessed other students' intervention to put a stop to bullying had a lower level of stress compared to Korean adoptees who did not witness other students' efforts to stop bullying $[t(29)=4.52, p<.001]$. Moreover, Korean adoptees who witnessed other students' intervention to put a stop to bullying $(M=84, S D=8.4)$ had a higher level of social support than Korean adoptees who did not witness other students' effort to stop bullying $(M=76.3, S D=8.4),[t(29)=-2.15, p<.05]$. This means that other students' intervention may be a moderating factor to lower stress levels among Korean adoptees.

Furthermore, this study found that the teachers or other adults' intervention may be a moderating factor to lower stress levels among Korean adoptees $[F(2,28)=8.795, p<.001]$. Our analysis indicated that Korean adoptees who had almost always witnessed their teachers or other adults intervene to stop bullying had a lower level of stress $(M=12.95, S D=6.36)$ than Korean adoptees who never witnessed their teacher intervene during bullying incidents $(M=19.6, S D=3.6)$. Interestingly, this analysis found that students who witnessed their teachers or other adults intervene once in a while or sometimes experienced a higher level of stress $(M=24.95, S D=6.36)$ as compared to students who had always or never witnessed their teachers' or other adults' intervention to put a stop to bullying.

Table 2 T-test Results of Asian Adoptees' Bullying Experience and Peer Intervention.

\begin{tabular}{lllll}
\hline Perceived Stress Scale & Mean & SD & $\boldsymbol{d f}$ & $\boldsymbol{t}$ \\
\hline Bullying Experience & 19.57 & 7.9 & 29 & $-2.1^{*}$ \\
No Bullying Experience & 13.81 & 7.2 & & \\
Students' Intervention & 14 & 5.1 & 29 & $4.52^{* *}$ \\
No Students' Intervention & 25 & 6.1 & & \\
\hline Perceived Social Support Scale & Mean & $\boldsymbol{S D}$ & $\boldsymbol{d f}$ & $\boldsymbol{t}$ \\
\hline Students' Intervention & 84 & 8.4 & 29 & $-2.15^{*}$ \\
No Students' Intervention & 76 & 8.5 & &
\end{tabular}

Table 3 ANOVA Results of Teacher or Adult Intervention on Perceived Stress Scale

\begin{tabular}{llll}
\hline Variable & Frequency of Witnessing Intervention & Mean differences & SD \\
\hline Teachers' or & Almost always witnessed their teacher or other adult & 12.95 & 6.36 \\
Other Adults & intervention & 19.6 & 6.36 \\
Intervention & Never witnessed their teacher or other adult intervention & 24.95 & 6.36 \\
& Witnessed their teacher or other adult intervention once a while & & \\
& or sometimes & & \\
\hline
\end{tabular}

$p<.001^{* * *}, \mathrm{~F}$-value $=8.795, \mathrm{~N}=31$ 


\section{Discussion/ Implication}

This is one of the first studies on school bullying experiences of Korean-born adoptees in white families in the U.S. Notably, the findings of this unique study supported the main hypothesis that among Korean adoptees in U.S. based families bullying in school is linked to perceived psychological stress. Our study provides preliminary evidence that Korean adoptees' adaptation to their new family and social environments is undermined by the stress of school bullying.

As mentioned earlier, the adoption process can be a stressful process for an adoptee and have negative implications for a child's health and well-being (Brodzinsky, Smith, \& Brodzinsky, 1998; Nickman, et al., 2005; Saiz \& Main, 2004). These risks may be exacerbated for Korean born adoptees to White families in the U. S., who may easily feel marginalized and potentially have low self-esteem (Mohanty \& Newhill, 2011) and/or lower well-being in their adopted status (Mohanty, 2013; Lee, Lee, Hu, \& Kim, 2014). Adding in the visibility factor documented by Docan-Morgan (2010) of Korean (Asian)-adoptees with White U.S. parents and the corresponding, lifelong intrusive interactions, Korean adoptees with White U.S. parents may also be greater targets for school-bullying. Our study provides preliminary evidence of this phenomenon.

Our results showed that Korean adoptees who witnessed other students' intervention to put a stop to bullying showed a lower level of stress compared to Korean adoptees who did not witness other students' efforts to stop the bullying. In addition, Korean adoptees who witnessed other students' intervention to put a stop to bullying had a higher level of social support than Korean adoptees who did not witness other students' efforts to stop bullying. Naturally, school children who received support from their peers who intervened to stop them from being bullied will feel less stress and will also feel socially supported by their peers as a result. As a moderating effect, peer intervention in this situation has the potential as a positive factor in improving the health and wellbeing of Korean adoptees (Docan-Morgan, 2010). In fact, several studies show that peer intervention as a bystander to bullying produces a positive effect on bullied victims (Polanin, Espelage, \& Pigott, 2012; Morgan, 2012; Nese, Horner, Dickey, Stiller, \& Tomlanovich, 2014). An important implication of this finding is to provide a bullying prevention awareness program to students.

A similar finding was observed in the analysis of adult or teacher intervention of bullying. Korean adoptees who had almost always witnessed adults' or teachers' intervention to put a stop to bullying had a lower level of stress compared to Korean adoptees who never witnessed adults' or teachers' efforts to intervene during bullying incidents. Again, the process of an adult or a teacher intervening in a bullying event seems likely to decrease stress levels of the Korean adoptees. An important implication to this finding is to provide a bullying prevention program for teachers and adults as well.

Bauman's (2008) literature review of school bullying noted that prevention programs administered by elementary school counselors that were the best in educating students and teachers, and in decreasing school bullying events. Teachers who have their own personal values need to be more aware of bullying (Padget \& Notar, 2013; Yoon \& Bauman, 2014), 
and school counselors are well-equipped with the skills needed to educate the educators. This was further emphasized that school counselors are highly skilled in their communication and education of young students. Frequently students fill both the role of victim and bully complicating the forces of intervention even further. In a literature survey on school bullying in urban and rural environments (Herrick, 2014) it was noted that each grade level should have its own prevention program specifically targeted to the bullying that's most evident. Numerous programs aimed at involving student participation are named and described in the literature (Padgett \& Notar, 2013).

An additional and interesting observation from the analysis was the effect of inconsistent intervention by an adult or teacher. Korean adoptees who witnessed their teacher or an adult intervening once in a while or sometimes showed a higher level of stress than students who always or never witnessed their teacher or another adult intervene. The inconsistency of the one who has the authority, as a teacher or an adult, moderates higher stress levels of the Korean adoptees. These students are likely responding to the inconsistent support of their teacher or adult in the same way as one who is in an oppressive situation. They cannot rely on the inconsistent support, consequently, they must be very cautious around both the bully and their teacher or adult. In addition to the distrust of the bully, they must watch out for the teacher or the adult who seemingly supports the bully. The teacher or adult may then be perceived by the bullied student in the same light as the bully. The concept of the victimization is one frequently seen in domestic violence situations when the parent, who provides and protects, turns into the perpetrator. In terms of identity development, this finding further supports the need of increased awareness of those who are in charge (authority figures) to be consistent when taking action to intervene (Hawker \& Boulton, 2003; Brodzinsky, Smith, \& Brodzinsky, 1998; Nickman, et al., 2005; Saiz \& Main, 2004). With a consistent intervention a child is likely to perceive the message that they matter enough for someone else to intervene and put a stop to the bullying.

Consequently, their sense of identity may no longer solely depend on the social support from a peer, an adult or teacher. As the child develops their identity they may no longer live in fear about their appearance due to the social support they received. As they grow they may suffer less from the anticipated consequences of bullying stress and experience fewer mental health challenges as they age and develop (Mohanty \& Newhill, 2011; Mohanty, 2013; Lee, Lee, Hu \& Kim, 2014; Docan-Morgan, 2010).

Recent research has posited that adolescent bullying may be an adaptive evolutionary behavior (Book, Volk \& Hosker, 2011; Volk, Camilleri, Dane \& Marini, 2012). Within the framework of evolutionary behavior this requires that a behavior be both adaptive and heritable. Volk, Dane, Marini, and Vaillancourt (2015) found evidence supporting the adaptive nature of bullying in their study regarding increased mating opportunities for bullies over non-bullies. Ireland (2005) found that pure bullies reported fewer symptoms such as depression, insomnia and anxiety than non-bullies or victims of bullying. More mating opportunities, as well as, fewer negative symptoms seem to be consistent with what may be perceived as an adaptive evolutionary pressure to develop an adaptation such as bullying. 
Ball et al. (2008) found that $61 \%$ of the variation in bullying behavior was accounted for by genetic factors, the remainder being accounted for by unique environmental factors and Veenstra et al. (2005) gathered evidence that individual characteristics rather than parenting practice were better predictors for preadolescent bullying. These findings are consistent with a biologically based genetic component present in bullying behavior.

Adolescent bullying within an adaptationist evolutionary framework has been examined (Book, Volk \& Hosker, 2011; Volk, Camilleri, Dane \& Marini, 2012). One of these projects (Book, Volk \& Hosker, 2011) was aimed at distinguishing whether bullies tended to be aggressive in generalized terms, or whether they were more specific and selective in exerting their aggression to victims. The former being associated with a more generalized aggressive personality and consequently less likely to be adaptive as it would be more difficult to forge social connections as well. Evidence supported the model of reactive bullying being predicted most strongly by an inverse relationship with the Humility-Honesty personality factor and to also be surprisingly little different than non-bullies on the Agreeableness factor. The Humility-Honesty factor is an additional dimension to the traditional Big Five personality factors included in the HEXACO model of personality (Ashton \& Lee, 2007). This dynamic was interpreted as one which would allow a bully to selectively use aggression against weaker and more vulnerable victims to advance their social standing or material gain while maintaining social alliances with others (Book, Volker \& Hosker, 2011).

By viewing bullying activity through an adaptive lens, one may better understand the existence and prevalence of bullying activity. The results of our study indicate that victims' stress is reduced when supported by peers, adults and teachers. This aligns with the adaptive factor described above. It is important that this understanding is not mistaken for a justification or excusal of such behavior. It is the authors' opinion that the more clearly this dynamic is understood that the more effective actions taken to reduce bullying and its negative impacts on innocent victims will be. Specifically, a better understanding of the genetic influence on bullying will lead to more effective interventions to prevent and alleviate the suffering of victims.

An important implication of the findings is to provide bullying prevention awareness education to school administration, adoption agency staff, and prospective adoptive parents. Educating school administrators will enhance their ability to respond to bullying in their school. Adoption agency staff and prospective adoptive parents will benefit from bullying prevention awareness education by being better prepared to support adoptees who may be bullied and to be better able to identify the signs that their child is being bullied at school. It will also equip prospective parents with more skills in managing the effects of bullying on their child, if this happens to them.

As such, it is notable that Korean adoptees of white parents may be vulnerable to school bullying, but peer and adult intervention can protect these children from the negative effects of bullying. Teachers and social work professionals managing adoptions will want to attend to this dynamic in cases involving a Korean adoptee in white families. It is worth noting that counseling and mentoring emerged as the most significant service needs in a study by Kupel 
(2010) that examined the perceptions of Asian adoptees toward post adoption services. In addition, Kupel's study (2010) found that post adoption services were scare due to minimal funding. Our study lends support to the need of greater resources for post adoption services and funding in the area counseling and mentoring of Korean adoptees of white families.

Although this study was unique and helped to derive informative findings, it was not without limitations. Among the weaknesses of the study was the overall response rate of $19 \%$ which was lower than anticipated. Due to the confidential nature of adoptions it was important to secure the names of individual families. Consequently, the adoption agency agreed to assist with the recruitment process by confidentially identifying potential participants and mailing them the survey packet. As with most surveys, our study also had a low response rate. Many families may have wanted to put the reality of adoption behind them, and therefore may have chosen not to respond. In order to improve response rates, future researchers may benefit from avid exploration of a confidential means of participant recruitment of Korean adoptees.

Another limitation may be a lack of consideration regarding participants' varied geographic locations (i.e. urban, suburban, or rural) which may influence the overall study results. For example, higher rates of bullying related problems, such as, discipline problems, racial and ethnic tensions, and incidents of gang activity were reported by urban schools than suburban and/or rural schools (Robers, Kemp, Truman \& Snyder, 2013). Furthermore, most of the urban schools appeared to have a high student-teacher ratio because urban schools are located in densely populated areas (Preston, 2009). As a consequence, students from these urban school settings have inadequate services (2009) and receive less attention from their teachers which may impact the students' overall well-being. Based on the above example, Korean adoptees in urban school settings are more likely to be exposed to bullying at school than Korean adoptees in rural school settings. Moreover, those Korean adoptees who have been exposed to bullying at school may have high levels of stress due to inadequate student services to deal with bullying and a lack of awareness and recognition of school bullying by teachers. The opposite was observed by Herrick (2014) who found that rural students experienced significantly more name calling and threat of harm than urban students. However, our study participants were recruited from all over the United States, and there isn't a way to determine whether the participants were recruited from urban school settings or rural school settings. Thus, the study results may not be relevant in urban school settings or in rural school settings. Therefore, future study should focus on either urban school settings or rural school settings to provide effective intervention plan.

In spite of a low response rate and a lack of consideration regarding participants' varied geotropic locations, significant findings were derived from the data. Due to scarce research on bullying experiences of Korean adoptees in the United States, the findings are highly relevant to this group. However, it should be noted that the results of this study should be considered preliminary only and/or applied with caution to other Korean adoptees in US White families because of the low sample size. 


\section{Acknowledgement}

*This study was supported by the faculty research grant program from Northeastern State University.

\section{References}

Annual Report on Intercountry Adoption. (n.d.). United States Bureau of Consular Affairs. [Data file]. Retrieved from http://travel.state.gov/content/adoptionsabroad/en/about-us/statistics.html

Ashton, M. C., \& Lee, K. (2007). Empirical, theoretical, and practical advantages of the HEXACO model of personality structure. Personality and Social Psychology Review, 11, 150-166. https://doi.org/10.1177/1088868306294907

Ball, H. A., Arseneault, L., Taylor, A., Maughan, B., Caspi, A., \& Moffitt, T. E. (2008). Genetic and environmental influences on victims, bullies and bully-victims in childhood. $\begin{array}{llll}\text { Child Psychology and Pychiatry, 49(1), 112. } & \text { 104-12 }\end{array}$ https://doi.org/10.1111/j.1469-7610.2007.01821.x

Bauman, S. (2008). The role of elementary school counselors in reducing school bullying. Elementary School Journal, 108(5), 362-375. https://doi.org/10.1086/589467

Book, A. S., Volk, A. A., \& Hosker, A. (2011). Adolescent bullying and personality: An adaptive approach. Personality and Individual Differences, 52, 218-223. https://doi.org/10.1016/j.paid.2011.10.028

Brodzinsky, D. M., Smith, D. W., \& Brodzinsky, A. B. (1998). Children's adjustment to adoption: Developmental and clinical issues. Thousand Oaks, CA: Sage.

Carney, J. V., Hazler, R. J., Oh, I., Hibel, L. C., \& Granger, D. A. (2010). The relations between bullying exposures in middle childhood, anxiety, and adrenocortical activity. Journal of School Violence, 9(2), 194-211. https://doi.org/10.1080/15388220903479602

Cohen, S., Kamarck, T., \& Mermelstein, R. (1983). A global measure of perceived stress. Journal of Health and Social Behavior, 24, 385-396. https://doi.org/10.2307/2136404

Cowie, H. (2011). Peer support as an intervention to counteract school bullying: Listen to the children. Children \& Society, 25, 287-292. https://doi.org/10.1111/j.1099-0860.2011.00375.x

Cutrona, C. E., Russell, D., \& Rose, J. (1984). Psychosocial factors and physical and mental health among the elderly. Unpublished manuscript.

Davidson, L. M., \& Demaray, M. K. (2007). Social support as a moderator between victimization and internalizing-externalizing distress from bullying. School Psychology Review, 36(3), 383-405. Retrieved from http://search.proquest.com/docview/621903930?accountid=3320

Denny, S., Clark, T. C., Fleming, T., \& Wall, M. (2004). Emotional resilience: Risk and protective factors for depression among alternative education students in New Zealand. 
https://doi.org/10.1037/0002-9432.74.2.137

Docan-Morgan, S. (2010). Korean adoptees' retrospective reports of intrusive interactions: Exploring boundary management in adoptive families. Journal of Family Communication, 10(3), 137-157. https://doi.org/10.1080/15267431003699603

Estévez, E., Murgui, S., \& Musitu, G. (2009). Psychological adjustment in bullies and victims of school violence. European Journal of Psychology of Education, 24(4), 473-483. https://doi.org/10.1007/BF03178762

Hawker, D. S. J., \& Boulton, M. J. (2003). Twenty years' research on peer victimization and psychosocial maladjustment: A meta-analytic review of cross-sectional studies. Brunner-Routledge, New York, NY.

Herrick, S. (2014). School bullying inurban and rural environments. Sociation Today, 12(2).

Hirschstein, M. K., Van Schoiack, E. L., Frey, K. S., Snell, J. L., \& MacKenzie, E. P. (2007). Walking the talk in bullying prevention: Teacher implementation variables related to initial impact of the Steps to Respect Program. School Psychology Review, 36(1), 3-21.

Holt, M. K., \& Espelage, D. L. (2007). Perceived social support among bullies, victims, and bully-victims. Journal of Youth and Adolescence, 36(8), 984-994. https://doi.org/10.1007/s10964-006-9153-3

Ireland, J. L. (2005). Psychological health and bullying behavior among adolescent prisoners: A study of young and juvenile offenders. Adolescent Health, 36, 236-243. https://doi.org/10.1016/j.jadohealth.2004.02.026

Kaltiala-Heino, R., Rimpelä, M., Rantanen, P., \& Rimpelä, A. (2000). Bullying at school—an indicator of adolescents at risk for mental disorders. Journal of Adolescence, 23(6), 661-674. https://doi.org/10.1006/jado.2000.0351

Kaplan, C. P., Turner, S., Norman, E., \& Stillson, K. (1996). Promoting resilience strategies: A modified consultation model. Social Work in Education, 18(3), 158-168. https://doi.org/10.1093/cs/18.3.158

Kupel, N. J. (2010). Asian adoptees and post-adoption services in Massachusetts: Data from providers and reflections from adult adoptees. Institute for Asian American Studies Publications, 4(1), 28.

Lee, J. P., Lee, R. M., Hu, A. W., \& Kim, O. M. (2014). Ethnic identity as a moderator against discrimination for transracially and transnationally adopted Korean American adolescents. Asian American Journal of Psychology. https://doi.org/10.1037/a0038360

McCormac, M. (2015). Preventing and responding to bullying: An elementary school's 4-year journey. Professional School Counseling, 18(1), 1-14. https://doi.org/10.5330/prsc.18.1.55607227n4428tkp

Mohanty, J. (2013). Ethnic and racial socialization and self-esteem of Asian adoptees: The 
mediating role of multiple identities. Journal of Adolescence, 36(1), 161-170. https://doi.org/10.1016/j.adolescence.2012.10.003

Mohanty, J., \& Newhill, C. E. (2011). Asian adolescent and young adult adoptees' psychological well-being: Examining the mediating role of marginality. Children \& Youth Services Review, 33(7), 1189-1195. https://doi.org/10.1016/j.childyouth.2011.02.016

Morgan, H. (2012). What teachers and schools can do to control the growing problem of school bullying. The Clearing House, 85, 174-178. https://doi.org/10.1080/00098655.2012.677075

Nese, R. N., Horner, R. H., Dickey, C. R., Stiller, B., \& Tomlanovich, A. (2014). Decreasing bullying behaviors in middle school: Expect Respect. School Psychology Quarterly, 29(3), 272-286. https://doi.org/10.1037/spq0000070

Nickman, S. L., Rosenfeld, A. A., Fine, P., Macintyre, J. C., Pilowsky, D. J., Howe, R., ... Sveda, S. A. (2005). Children in adoptive families: Overview and update. Journal of the American Academy of Child \& Adolescent Psychiatry, 44(10), 987-995. https://doi.org/10.1097/01.chi.0000174463.60987.69

Olweus, D. (2007). The Olweus Bullying Questionnaire. Center City, MN: Hazelden. https://doi.org/10.1037/t56255-000

Padgett, S., \& Notar, C. E. (2013). Anti-bullying programs for middle/high schools. National Social Science Journal, 40(1), 88-93.

Polanin, J. R., Espelage, D. L., \& Pigott, T. D. (2012). A meta-analysis of school-based bullying prevention programs' effects on bystander intervention behavior. School Psychology Review, 41(1), 47-65.

Polk, L. V. (1997). Toward a middle-range theory of resilience. Advances in Nursing Science, 19(3), 1-13. https://doi.org/10.1097/00012272-199703000-00002

Preston, J. P. (2009). Rural and urban teaching experiences: Crossing borders. VDM Publishing:

Raaska, H., Lapinleimu, H., Sinkkonen, J., Salmivalli, C., Matomäki, J., Mäkipää, S., \& Elovainio, M. (2012). Experiences of School Bullying Among Internationally Adopted Children: Results from the Finnish Adoption (FINADO) Study. Child Psychiatry \& Human Development, 43(4), 592-611. https://doi.org/10.1007/s10578-012-0286-1

Robers, S., Kemp, J., Truman, J., \& Snyder, T. D. (2013). Indicators of school crime and safety. 2012 (NCES 2013-036/NCJ 241446). National Center for Education Statistics, U.S. Department of Education, and Bureau of Justice Statistics, Office of Justice Programs. Washing-ton, DC: U.S. Department of Justice.

Saiz, S. G., \& Main, F. O. (2004). A Comparison of the Early Recollections of Adults Who Were Adopted as Children and Adults Who Were Not Adopted. Journal of Individual Psychology, 60(2), 175-190. 


\section{Macrothink}

Son, E., Parish, S. L., \& Peterson, N. A. (2012). National prevalence of peer victimization among young children with disabilities in the United States. Children \& Youth Services Review, 34(8), 1540-1545. https://doi.org/10.1016/j.childyouth.2012.04.014

Veenstra, R., Lindenberg, S., Oldehinkel, A. J., Winter, A. F., Verhulst, F. C., \& Ormel, J. (2005). Bullying and victimization in elementary schools: A comparison of bullies, victims, bully/victims, and uninvolved preadolescents. Developmental Psychology, 41(4), 672-682. https://doi.org/10.1037/0012-1649.41.4.672

Volk, A. A., Dane, A. V., Marini, A. F., \& Vaillancourt, T. (2015) Adolescent Bullying, Dating, and Mating: Testing an Evolutionary Hypothesis. Evolutionary Psychology, 1-11. https://doi.org/10.1177/1474704915613909

\section{Copyrights}

Copyright for this article is retained by the author(s), with first publication rights granted to the journal.

This is an open-access article distributed under the terms and conditions of the Creative Commons Attribution license (http://creativecommons.org/licenses/by/4.0/). 